\title{
BMJ Open Community-randomised controlled trial embedded in the Anishinaabek Cervical Cancer Screening Study: human papillomavirus self-sampling versus Papanicolaou cytology
}

Ingeborg Zehbe, ${ }^{1,2,3}$ Robert Jackson, ${ }^{1,4}$ Brianne Wood, ${ }^{5}$ Bruce Weaver, ${ }^{3}$ Nicholas Escott, ${ }^{3,6}$ Alberto Severini, ${ }^{7}$ Mel Krajden, ${ }^{8}$ Lisa Bishop, ${ }^{2}$ Kyla Morrisseau, ${ }^{2}$ Gina Ogilvie, ${ }^{8,9}$ Ann N Burchell, ${ }^{10,11}$ Julian Little ${ }^{5}$

To cite: Zehbe I, Jackson R, Wood B, et al. Communityrandomised controlled trial embedded in the Anishinaabek Cervical Cancer Screening Study: human papillomavirus self-sampling versus Papanicolaou cytology. BMJ Open 2016;6 e011754. doi:10.1136/ bmjopen-2016-011754

- Prepublication history and additional material is available. To view please visit the journal (http://dx.doi.org/ 10.1136/bmjopen-2016011754).

Received 2 March 2016 Revised 19 July 2016 Accepted 6 September 2016

CrossMark

For numbered affiliations see end of article.

Correspondence to Dr Ingeborg Zehbe; zehbei@tbh.net

\section{ABSTRACT}

Objectives: The incidence of cervical cancer is up to 20 -fold higher among First Nations women in Canada than the general population, probably due to lower participation in screening. Offering human papillomavirus (HPV) self-sampling in place of Papanicolaou (Pap) testing may eventually increase screening participation and reduce cervical cancer rates in this population.

Design: A community-randomised controlled screening trial.

Setting: First Nations communities in Northwest Ontario, Canada.

Participants: Women aged between 25 and 69, living in Robinson Superior Treaty First Nations. The community was the unit of randomisation.

Interventions: Women were asked to complete a questionnaire and have screening by HPV self-sampling (arm A) or Pap testing (arm B).

Primary outcome measures: The number of women who participated in cervical screening.

Randomisation: Community clusters were randomised to include approximately equivalent numbers of women in each arm.

Results: 6 communities were randomised to arm A and 5 to arm B. One community withdrew, leaving 5 communities in each group (834 eligible women). Participation was $<25 \%$. Using clustered intention-totreat (ITT) analysis, initial and cumulative averaged uptakes in arm A were 1.4 -fold (20\% vs $14.3 \%$, $\mathrm{p}=0.628)$ and 1.3 -fold $(20.6 \%$ vs $16 \%, p=0.694)$ higher compared to arm B, respectively. Corresponding per protocol (PP) analysis indicates 2.2-fold (22.9\% vs $10.6 \%, p=0.305)$ and 1.6 -fold $(22.9 \%$ vs $14.1 \%$, $p=0.448$ ) higher uptakes in arm A compared to arm B. Screening uptake varied between communities (range 0-62.1\%). Among women who completed a questionnaire $(18.3 \%$ in $\operatorname{arm} A, 21.7 \%$ in $\operatorname{arm} B)$, the screening uptake was 1.8 -fold (ITT; $p=0.1132)$ or 3 fold (PP; $p<0.01$ ) higher in arm A versus arm $B$. Conclusions: Pap and HPV self-sampling were compared in a marginalised, Canadian population.

\section{Strengths and limitations of this study}

- The Anishinaabek Cervical Cancer Screening Study (ACCSS) addresses a health disparity in Canada, namely higher cervical cancer incidence in Indigenous compared to non-Indigenous women.

- Participatory action research facilitated such a study for the first time in First Nations women in Northwest Ontario.

- A randomised controlled trial comparing Papanicolaou versus HPV self-sampling was implemented in this population involving community lay health workers to recruit screening participants.

- The longitudinal approach of the ACCSS will increase awareness for the benefit of cervical screening in underserved populations.

- More collaborative work with the ACCSS partner communities based on innovative, communityshaped health promotions is necessary to elucidate ways in which to reach the women, who remain underscreened.

Results indicated a preference for self-sampling. More research on how to reach underscreened Indigenous women is necessary.

Trial registration number: ISRCTN84617261.

\section{INTRODUCTION}

Cervical screening programmes, mainly based on Papanicolaou (Pap) testing, followed by management of detected precancerous cervical lesions, have reduced cervical cancer incidence and mortality in most developed countries by more than half. ${ }^{1}{ }^{2}$ However, Indigenous populations worldwide continue to experience a disproportionate 
burden of cervical cancer morbidity and mortality. ${ }^{3}$ In Canada, women from First Nations, Métis and Inuit communities can have a 2-fold to 20-fold higher rate of cervical cancer than non-Indigenous women. ${ }^{4-6}$ This is probably a consequence of non-participation in screening or challenges with accessing follow-up care. ${ }^{7}$

Human papillomavirus (HPV) DNA testing has an overall greater sensitivity than traditional Pap cytology to detect lesions classified as cervical intraepithelial neoplasia grade 2 or higher. ${ }^{8}$ In addition, self-collection of these samples for HPV testing may help engage women who would not otherwise participate in standard-of-care Pap cervical screening due to factors such as geographical isolation and cultural sensitivity. ${ }^{9} 10 \quad$ In an Argentinian, cluster-randomised, controlled trial, selfsample collection resulted in a 4-fold higher screening uptake than HPV sampling performed by a clinician ${ }^{11}$ and we hypothesised that a similar approach could potentially increase screening uptake within Northwest Ontario First Nations communities that have aboveaverage cervical cancer rates. ${ }^{12} 13$

In populations such as First Nations, community-based participatory action research (PAR) is recognised to be an appropriate approach as it focuses on community engagement, collaboration and reflection throughout the process design, implementation and dissemination of the research. ${ }^{14}{ }^{15}$ Accordingly, the Anishinaabek Cervical Cancer Screening Study (ACCSS), using a unique mixed methods approach, was developed with 11 partner communities in Northwest Ontario, Canada. The main objective was to assess whether, within a PAR framework, screening participation increases in the First Nations population when HPV self-sampling instead of Pap testing is offered. After conducting interviews as well as focus groups with healthcare providers (HCPs) and women living on reserves about cervical cancer screening barriers (qualitative component), ${ }^{16-18}$ we performed a community-randomised controlled trial (quantitative component). Here, we present the results of the ACCSS quantitative component-the screening trial.

\section{METHODS}

The method sections below are detailed according to CONSORT guidelines. ${ }^{19} 20$ The full trial protocol according to SPIRIT checklist ${ }^{21} 22$ is provided in online supplementary data 1 . Model informed consent forms, as well as baseline and follow-up questionnaires, can be accessed in online supplementary data 2. Online supplementary table A summarises community events during the trial and online supplementary table B summarises the HPV typing results.

\section{Trial design}

We performed a two-arm, community-randomised controlled trial with 11 First Nations communities in the Thunder Bay district of Northwest Ontario, Canada. We stratified community clusters according to the total number of registered women. By conducting a stratified randomisation as detailed below, we intended for approximately equivalent numbers of women to be offered screening in each arm and to minimise bias introduced by preference of study participants or HCPs.

\section{Participants}

We identified 1002 eligible women (denominator) between 25 and 69 years old as being band members in one of the 11 participating First Nations communities and living on their own or another reserve, on Crown land or off-reserve with their main address in the Thunder Bay district (table 1). ${ }^{23}$ We excluded women who were pregnant from the study but arranged that they could participate after they had given birth. Participation in the trial could be through answering a

Table 1 Count of eligible and participating women in each partner community (band)

\begin{tabular}{|c|c|c|c|c|c|c|c|c|c|c|c|}
\hline \multirow[b]{2}{*}{ Band } & \multirow[b]{2}{*}{ Arm } & \multirow{2}{*}{$\begin{array}{l}\text { Eligible } \\
\text { women* }^{*}\end{array}$} & \multicolumn{3}{|c|}{ Baseline questionnaires } & \multicolumn{3}{|c|}{ Screened, intention to treat } & \multicolumn{3}{|c|}{ Screened, per protocol } \\
\hline & & & Phase I & Phase II & Both† & Phase I & Phase II & Both† & Phase I & Phase II & Both† \\
\hline 1 & $A$ & 29 & 18 & 1 & 19 & 18 & 1 & 19 & 18 & 0 & 18 \\
\hline 2 & $A$ & 30 & 11 & 0 & 11 & 8 & 0 & 8 & 11 & 0 & 11 \\
\hline 3 & $A$ & 70 & 1 & 0 & 1 & 1 & 0 & 1 & 2 & 0 & 2 \\
\hline 4 & $A$ & 80 & 14 & 3 & 17 & 13 & 0 & 13 & 13 & 0 & 13 \\
\hline 5 & $A$ & 84 & 15 & 0 & 15 & 4 & 0 & 4 & 9 & 0 & 9 \\
\hline 6 & $A$ & 111 & 15 & 0 & 15 & 10 & 0 & 10 & 10 & 0 & 10 \\
\hline 7 & B & 17 & 11 & 0 & 11 & 8 & 0 & 8 & 4 & 1 & 5 \\
\hline 8 & $\mathrm{~B}$ & 71 & 28 & 8 & 36 & 5 & 5 & 10 & 5 & 5 & 10 \\
\hline 9 & $\mathrm{~B}$ & 88 & 27 & 1 & 28 & 12 & 1 & 13 & 7 & 1 & 8 \\
\hline $10 \ddagger$ & $\mathrm{B}$ & 168 & 0 & 0 & 0 & 0 & 0 & 0 & NA & NA & NA \\
\hline 11 & $\mathrm{~B}$ & 254 & 28 & 1 & 29 & 10 & 0 & 10 & 10 & 0 & 10 \\
\hline Total & & $1002(834) \ddagger$ & 168 & 14 & 182 & 89 & 7 & 96 & 89 & 7 & 96 \\
\hline
\end{tabular}


baseline questionnaire (see online supplementary data 2) or through answering a baseline questionnaire and getting screened. As part of PAR, ${ }^{15}$ we hired and engaged with community-based research assistants (CBRAs) to facilitate the implementation of the screening modalities and collection of data in their respective communities.

The First Nations partner communities (11 clusters) each have between $\sim 70$ and 800 band members and are scattered around the shores of Lake Superior and Lake Nipigon in Northwest Ontario, Canada. ${ }^{12}{ }^{13}$ During an All Chiefs' meeting in Thunder Bay (November 2010) representing the Robinson Superior Treaty communities, to which Ingeborg Zehbe was invited, the then attending chiefs decided to participate in the proposed cervical screening study. Henceforth, any of these communities was eligible to join the study whereupon research agreements were ratified individually with each participating community between December 2010 and June 2011.

\section{Interventions}

Communities were randomised to either the intervention group (arm A) or control group (arm B). Each arm consisted of a first offer of a screening modality in phase I lasting 3 months, followed by a 1-2-month intervention break, and finally the phase II cross-over period in which women were offered the alternate screening method. In the intervention group $(\operatorname{arm} \mathrm{A})$, women were first offered HPV testing using self-sampling and in the control group ( $\operatorname{arm} \mathrm{B}$ ), women were first offered Pap testing. CBRAs invited women to participate in the ACCSS trial after an educational event and other recruitment strategies (see online supplementary table A). CBRAs obtained written informed (individual) consent from the participants and helped them to complete baseline and follow-up questionnaires.

For HPV DNA testing, the CBRAs provided the selfsampling kits and the participants were asked how they wished to be contacted in the event of a positive HPV test result. If a participant was found to have a high-risk infection (see online supplementary table B), she was referred for a follow-up (Pap test). For Pap testing, CBRAs scheduled appointments either directly with HCPs or through Well-Women clinics. Sample collection, processing, communication and follow-up were performed according to the Ontario Cervical Screening protocol for primary care practitioners. ${ }^{24}$

\section{Outcomes}

The primary outcomes of the trial were initial and cumulative screening uptakes as well as participant psychosocial status. Initial screening uptake was defined as the number of women who provided informed consent, completed a baseline questionnaire (online supplementary protocol appendix) and provided a selfsample or underwent a Pap test following the initial screening offer, divided by the eligible number of women registered in their community as of January $2014 .^{23}$ For cumulative screening uptake, the numerator was defined as for initial uptake, except that participation was in either the initial or the subsequent screening offer; the denominator was defined as above. Psychosocial status included domains of worries/concerns about cancer, self-efficacy and external factors. A secondary outcome reported comfort with the screening experience.

\section{Sample size and power estimations}

When designing the ACCSS trial, data regarding cervical cancer screening rates in Ontario Indigenous women were not available. As First Nations women in Ontario are twice as likely to develop cervical cancer compared to the mainstream population, ${ }^{4}$ we calculated that the proportion of women eligible to be screened in First Nations communities in Northwest Ontario, and who had a Pap test in the previous 3 years, was half the general population uptake of $45 \%$, that is, $22.5 \%$. Previous studies report that between $32 \%$ and $58 \%$ (mean $45 \%$ ) of women who have not had a Pap test during the last 6 years accepted an offer of selfsampling. ${ }^{25-27}$ We estimated three scenarios to illustrate the range of power we might have with a given sample size of $\sim 1000$ women: (1) no change in screening uptake in the arm initially offered Pap testing, uptake $45 \%$ higher in the other arm, that is, $32.5 \%$; (2) uptake in the arm initially offered Pap testing $30 \%$, and $43.5 \%$ in the other arm; and (3) uptake in the arm initially offered Pap testing 45\%, and $65.3 \%$ in the other arm. If clustering were disregarded in the power calculations, then, with $\sim 500$ participants per arm, at $5 \% \alpha$ level, the trial would have an average power of $>96 \%$ to detect a difference in uptake for all three scenarios. Because of the potential for individuals' responses to the interventions within communities to be correlated, clustering had to be taken into account. Previous work on intracluster correlation (ICC) in the situation of variable cluster size ${ }^{28-30}$ suggests that the ICC would likely be less than the estimated maximum values (scenario 1: 0.0063, scenario 2: 0.0158 , scenario 3: 0.0461 ), meaning that a sample size of 500 participants per arm would be adequate to achieve $80 \%$ power.

\section{Randomisation}

We stratified communities according to size (small, medium and large) and randomly assigned them to the first offer intervention type within their strata. Using band registration numbers from January $2013,{ }^{13}$ we defined a small community as $\leq 360$ total registered females, a medium community as between 361 and 910 total registered females and a large community as more than 910 total registered females. There were seven medium communities, three small communities and one large community. By conducting a stratified randomisation, we intended for approximately equivalent numbers of women to be offered screening in each arm. 
We randomised communities instead of individuals, to build on the community engagement element of the project as well as to reduce contamination between the control group (those who were first offered Pap testing) and the intervention group (those who were first offered the HPV self-test). A research assistant external to the Research Team performed the randomisation. First, we randomly assigned the seven medium sized communities. To do so, each community was assigned a random number and then those with the four highest numbers were placed into one arm and the remaining three into the other arm. We then applied the same approach to the three smaller communities. Finally, we placed the one large community in the arm with only three medium-sized communities in it.

\section{Statistical methods}

Screening uptake was determined by intention-to-treat (ITT) and per protocol (PP) analyses, in recognition of limitations with both approaches. ${ }^{31-35}$ Thus, in the ITT analysis, women from a community that terminated its participation in the trial were included in the analysis as having no screening uptake. Women who did not answer the questionnaire were assumed not to have accepted the offer of screening. However, women who received a screening test that was not of the type offered were included as if they had accepted the offer of the test that had been assigned to their community. In the PP analysis, women from a community that terminated its participation in the trial were excluded from analysis. Women who did not answer the questionnaire were assumed not to have accepted the offer of screening and analysis was based on the type of test that the women had actually undergone. For cluster-level analysis, we compared the proportion of cervical cancer screening uptake between screening modalities using a permutation test. ${ }^{28}$ Percentage point (or 'risk') difference with a $95 \%$ CI was reported as calculated by the bootstrap method. ${ }^{36}$ To account for differences in questionnaire response, a proxy for CBRA outreach and community participation, additional analysis of the clustered screening uptake data was completed by restricting it to the subset of women who completed baseline questionnaires in each community.

The assessment of psychosocial status used a nine-item instrument with domains of worries/concerns about cancer, self-efficacy and external factors such as the community and relationships, based on similar published instruments. ${ }^{37}{ }^{38}$ Each item was a seven-point Likert-type item. Psychosocial scores were obtained by calculating a mean score of all completed items for each respondent (after reverse-coding items 2, 4 and 8). We compared PP community-averaged baseline scores obtained at the time of intervention rollout in each community between the arms, irrespective of whether the women had accepted the offer of a screening test. We intended that this would reflect the response to the educational and engagement component of the intervention at the community level. We computed means and $95 \%$ CIs (as described above), and tested for the difference between the arms by a permutation test. In a descriptive analysis, we computed the scores at follow-up time points 1 and 2 between the arms, regardless of community, to assess psychosocial scores before and after screening. We also compared scores between screened and not screened women.

We applied standard descriptive statistics to the nonclustered data, sociodemographic characteristics, health status and health service use as well as comfort with either screening modality. We compared this information between the arms using the $\chi^{2}$ test, $\mathrm{N}-1 \chi^{2}$ test for $2 \times 2$ tables with any low $(<5)$ expected counts, ${ }^{39}$ the linear-by-linear association test for ordinal data, ${ }^{40}$ the Mantel-Haenszel $\chi^{2}$ test for stratified data, or the Welch's t-test for comfort scores. All statistical analyses were conducted using R V.3.1.0 (R: A language and environment for statistical computing. Vienna, Austria: R Foundation for Statistical Computing. 2014. http:/ /www.R-project.org/ (accessed $26 \mathrm{Jul} 2015)$ ) except for the linear-by-linear association test for which SPSS V.22 for Windows was used (IBM Corp. Released 2013. IBM SPSS Statistics for Windows, Version 22.0. Armonk, NY: IBM Corp. http:// www-01.ibm.com/support/docview.wss? uid=swg21476197 (accessed 30 Apr 2015)). The $\alpha$ level was 0.05 .

\section{RESULTS}

\section{Screening uptake}

Six communities were randomised to arm $\mathrm{A}$ and the other five were randomised to arm B, with a total of 1002 eligible women. One community in arm B withdrew, resulting in 834 eligible women remaining (table 1). ${ }^{23}$ Enrolment in the trial was initiated in the communities between May and November 2013, with the initial screening offer being made in each community for a 3-month period, followed by a 1-2-month intervention break, and then the second offer of screening. Participant recruitment was completed in August 2014. Follow-up questionnaires were provided after 6 weeks following the completion of each 3-month screening round.

Using clustered ITT analysis (figure 1 and table 2), the community average uptake of screening in response to an initial offer of an HPV test based on self-sampling (arm A) was $20.0 \%$, compared with $14.3 \%$ in the arm initially offered a Pap test (arm B): 1.4-fold increase, difference of $5.7 \%$ (95\% CI -11.6 to $34.0, \mathrm{p}=0.628$ ).

The cumulative uptake of screening was $20.6 \%$ in arm $\mathrm{A}$ and $16.0 \%$ in arm B: 1.3-fold increase, difference of $4.6 \%$ (95\% CI -13.9 to $32.3, \mathrm{p}=0.694$, permutation test). Compared to the a priori screening uptake estimate for Pap testing versus HPV self-sampling, the average screening uptake in phase I was lower than that was expected (estimated to be at least $22.5 \%$ vs $32.5 \%$, respectively, ie, for scenario 1) but the difference in uptake between both modalities was close to the estimate $(45 \%)$ at $40 \%$.

Using clustered PP analysis (figure 1 and table 2), the average uptake of screening after the initial offer was 


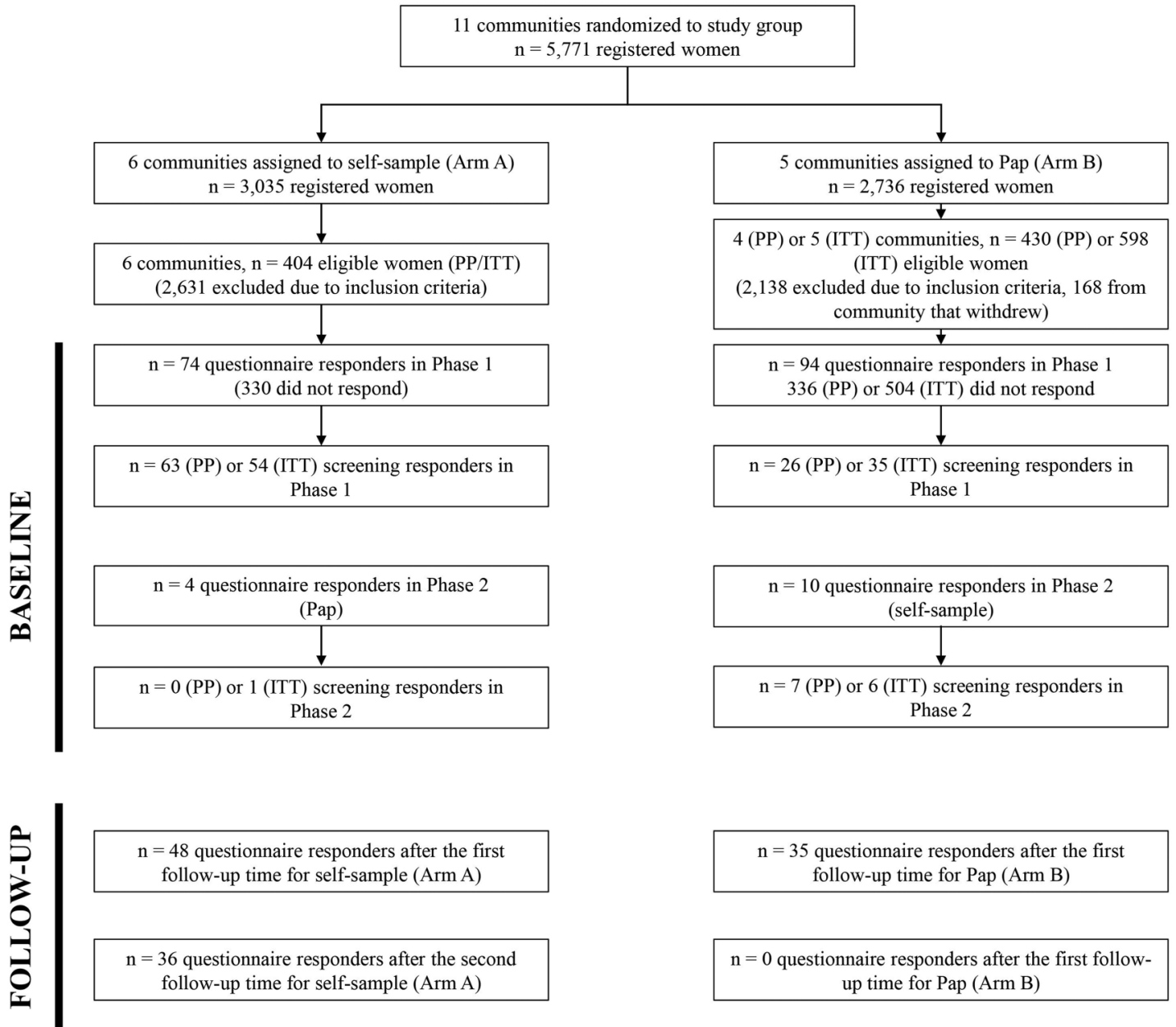

Figure 1 Overview of the Anishinaabek Cervical Cancer Screening Study. The figure illustrates the breakdown of participants during the study, from recruitment to second follow-up.

$22.9 \%$ in arm $\mathrm{A}$ and $10.6 \%$ in arm B: 2.2-fold increase, difference of $12.3 \%$ (95\% CI 2.4 to $46.6, \mathrm{p}=0.305$, permutation test). The cumulative uptake of screening was $22.9 \%$ in arm $\mathrm{A}$ and $14.1 \%$ in arm B: 1.6-fold increase, difference of $8.8 \%$ (95\% CI -4.7 to 39.6 , $\mathrm{p}=0.448$, permutation test).

Compared to the a priori screening uptake estimate for Pap testing versus HPV self-sampling, the average screening uptake in phase I was lower than that was expected (estimated to be at least $22.5 \%$ vs $32.5 \%$, respectively, ie, for scenario 1) but the difference in uptake between both modalities was higher than that was estimated $(45 \%)$ at $96 \%$.

Of the self-collected HPV test samples, 96.3\% (78 of 81) were adequate for DNA analysis and of these, $19.2 \%$ tested positive for high-risk HPV types associated with cervical dysplasia (see online supplementary protocol and table 3B).

The proportion of screening uptake varied highly between communities/bands (table 1). At the end of phase I, the screening uptake ranged from $0.0 \%$ to $62.1 \%$ (ITT) or $2.9 \%$ to $62.1 \%$ (PP) among communities first offered self-sampling and from $0.0 \%$ to $47.1 \%$
(ITT) or $3.9 \%$ to $23.5 \%$ (PP) among communities first offered Pap testing. Interestingly, compared to our a priori screening uptake estimate, the best expected outcome (scenario 3) was reflected in one community of each respective arm using ITT analysis: $62.1 \%$ for HPV self-sampling (community 1) and $47.1 \%$ for Pap testing (community 7). Using PP analysis, this difference was $62.1 \%$ vs $23.5 \%$ in favour of HPV self-sampling. In addition, using PP analysis, community 2 in arm A was similar to scenario 1 with an uptake of $37 \%$. Uptake in the other communities was all below the least estimated outcome (scenario 1). This diversity in uptake among communities motivated post hoc analyses to supplement those set forth as primary outcomes. By calculating the proportion of women who were screened in the subset of women who completed a questionnaire in phase I (18.3\% in arm A and $21.9 \%$ in arm B), the screening uptake was higher for HPV self-sampling compared to Pap testing: 1.8-fold (33.8\% difference) by ITT analysis; $\mathrm{p}=0.1132$ or 3 -fold $(57.6 \%$ difference) by PP analysis; $\mathrm{p}<0.01$.

Owing to the low participation rate in phase II, no further subgroup comparisons were attempted (figure 1). 


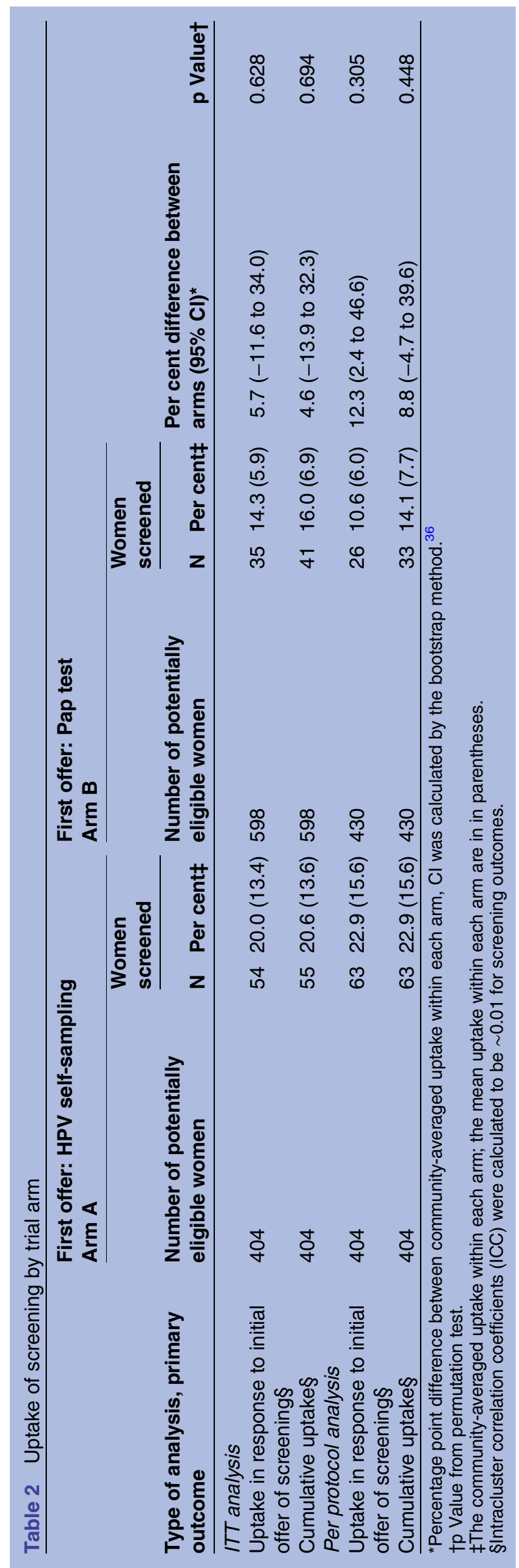

An age-covariate analysis was also originally planned, but was not possible given the lack of complete age data for non-respondent eligible women within each of the participating communities.

\section{Psychosocial impact on women who were screened}

For women who were screened and completed a follow-up questionnaire, mean psychosocial scores were not significantly different between baseline and follow-up times for arm A or arm B ( $p>0.05$ by permutation test) (table 3A). For all time points and both study arms, summed psychosocial scores ranged between 'slightly disagree' and 'neither agree nor disagree', corresponding to scores between 2 and 4 on a seven-point Likert-type item.

\section{Comfort level of women who were screened}

As part of the follow-up questionnaires, women who got screened were asked about their comfort with the screening experience, ranging from very uncomfortable (score of 1) to very comfortable (score of 5) (table 3B). For arm A, women who self-sampled rated their mean comfort level as $4.23 \pm 0.83$ SD (follow-up 1) and 4.26 \pm 1.02 SD (follow-up 2), indicating that they were comfortable to very comfortable with the experience. For Arm B, women who underwent Pap testing rated their mean comfort level as $3.75 \pm 1.21$ SD (only data from follow-up 1 available), indicating that they were neutral to comfortable ( $p=0.125$, Welch's t-test).

\section{Characteristics of women who answered a baseline questionnaire}

Socioeconomic and health demography characteristics were compared between the arms (tables 4 and 5). The age distributions were similar between the two arms, with the majority of women being $<50$ years of age. No significant differences in questionnaire responses between arms for sociodemographic or health characteristics were observed, apart from the difference in proportions of responders that lived on-reserve. This discrepancy is probably due to the fact that two communities still developing a land base for their band, and whose members by definition lived off-reserve, were both randomised to arm A.

While most questionnaire participants rated their health between 'Good' to 'Excellent', almost half of them stated their health was negatively impacted as a result of first-hand experience or familial encounters with residential schooling. Approximately two-thirds of all participating women reported that they had had a Pap test in the 3-year interval prior to completion of the baseline questionnaire. No significant difference in recent Pap history between arm A and B $(p=0.796)$ or stratified according to women screened or not screened within arm A $(p=0.756)$ and arm B $(p=0.899)$ was noted, as assessed by the Mantel-Haenszel $\chi^{2}$ test. 
Table 3 Psychosocial $^{*}$ and comfort scores from baseline and follow-up questionnaires

\begin{tabular}{|c|c|c|c|c|c|}
\hline \multirow[b]{2}{*}{ A. Questionnaire } & \multicolumn{2}{|c|}{$\begin{array}{l}\text { First offer: HPV self-sampling } \\
\text { Arm A }\end{array}$} & \multicolumn{2}{|l|}{$\begin{array}{l}\text { First offer: Pap test } \\
\text { Arm B }\end{array}$} & \multirow[b]{2}{*}{ p Valuet } \\
\hline & $\begin{array}{l}\text { Number of women } \\
\text { (responded) }\end{array}$ & $\begin{array}{l}\text { Mean } \\
(95 \% \mathrm{Cl}) \ddagger\end{array}$ & $\begin{array}{l}\text { Number of women } \\
\text { (responded) }\end{array}$ & $\begin{array}{l}\text { Mean } \\
(95 \% \mathrm{Cl}) \ddagger\end{array}$ & \\
\hline Baseline§ & $78(78)$ & 3.1 (2.8 to 3.3$)$ & $104(103)$ & 3.3 (3.1 to 3.7$)$ & 0.521 \\
\hline Follow-up $1 \S$ & $48(45)$ & $3.0(2.5$ to 3.3$)$ & $35(33)$ & $3.3(2.9$ to 4.0$)$ & 0.468 \\
\hline Follow-up 2 & $36(33)$ & 3.4 (3.2 to 3.7$)$ & $0(0)$ & - & - \\
\hline \multicolumn{6}{|c|}{ Secondary analysis based on screening response, descriptive, mean score (SD)ף } \\
\hline Baseline (screened) & $55(55)$ & $3.3(0.9)$ & $41(41)$ & $3.2(0.8)$ & - \\
\hline Baseline (not screened) & $23(23)$ & $3.3(0.8)$ & $63(62)$ & $3.4(0.7)$ & - \\
\hline Follow-up 1 (screened) & $41(41)$ & $3.1(0.8)$ & $22(22)$ & $3.2(0.9)$ & - \\
\hline Follow-up 1 (not screened) & $7(4)$ & $3.7(0.9)$ & $13(11)$ & $3.6(0.8)$ & - \\
\hline Follow-up 2 (screened) & $29(29)$ & $3.4(0.7)$ & - & - & - \\
\hline Follow-up 2 (not screened) & $7(4)$ & $3.1(1.0)$ & - & - & - \\
\hline \multicolumn{6}{|c|}{ B. Comfort level of screened women } \\
\hline Questionnaire & $\begin{array}{l}\text { HPV self-sampling } \\
\text { Mean score (SD) }\end{array}$ & & $\begin{array}{l}\text { Pap test Arm B } \\
\text { Mean score (SD) }\end{array}$ & & p Value $* \star$ \\
\hline Follow-up 1 & $4.23(0.83)$ & & $3.75(1.21)$ & & 0.125 \\
\hline Follow-up 2 & $4.26(1.02)$ & & - & & - \\
\hline \multicolumn{6}{|c|}{ 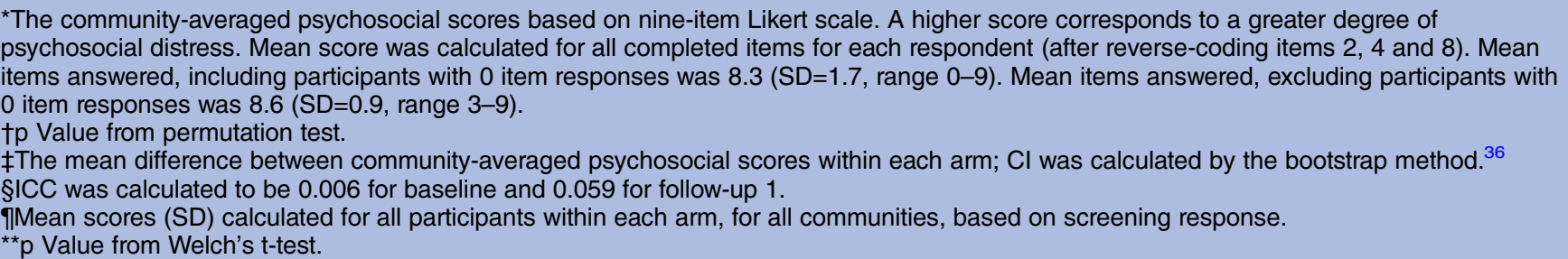 } \\
\hline
\end{tabular}

\section{DISCUSSION}

The ACCSS is the first mixed methods study under a PAR framework to qualitatively and quantitatively investigate cervical screening behaviours of First Nations women in Canada. ${ }^{13}$ We have been mindful to engage the partner communities throughout the research process to initiate a cancer screening culture reflecting the Anishinaabek 'Pimatisiwin' (good life based on good health) philosophy which included the implementation of a cervical screening trial comparing two screening modalities. We hypothesised that in a marginalised population with high cervical cancer rates and low screening participation, HPV self-sampling may be an appealing alternative to Pap testing. We reasoned that empowering women to take their own samples may help overcome some of the structural and cultural barriers First Nations women face when attending cervical screening ${ }^{13}$ - a re-affirmed notion and deemed to be culturally appropriate by our community informants during the qualitative phase of the ACCSS. ${ }^{17} 18$ DNA integrity from self-samples was excellent-an important factor to emphasise when promoting this screening method as some women reported being anxious that they were not taking their self-sample correctly. Greater than $95 \%$ of the samples could be HPV-tested and typed, confirming our earlier pilot data. ${ }^{12}$ Except for the higher employment rate, the sociodemographic characteristics of women who accepted the offer of screening and/or completed a questionnaire were similar to those of the region's Indigenous populations. ${ }^{41}{ }^{42}$ For instance, using food security responses as a proxy, we noticed higher, self-reported, impoverished living conditions compared to the general population. ${ }^{43}$

The average screening uptake was less than a quarter for either screening modality, which may be related to not being aware of the benefit of screening, general fear of cancer and colonial legacy (eg, mistrust of the healthcare system). The estimated screening uptake was achieved only in two communities of arm A and in one community of arm B. Notably, the uptake in each participating community varied considerably, and only clustered PP analysis of screening uptake relative to the number of women in each community who completed a questionnaire showed statistical significance in favour of HPV self-sampling. However, the absolute difference in uptake in favour of HPV self-sampling was close to (ITT) or even twice (PP) our a priori estimation. A similar increase in uptake of HPV self-sampling over Pap testing was obtained for European and North American underscreened women, ${ }^{44}$ underscoring its benefits for cervical screening participation. A shift in the comfort level was noted in favour of HPV self-sampling in the current study. A deeper, qualitative analysis comparing HPV self-sampling with HCP-administered Pap cytology 
Table 4 Socioeconomic demographics of women who provided a baseline questionnaire

\begin{tabular}{|c|c|c|c|c|c|}
\hline Type of characteristic & $\begin{array}{l}\text { First offer: HPV } \\
\text { self-sampling } \\
\text { Arm } A^{*} \dagger \\
\text { Total }=78 \\
\end{array}$ & $(\%)$ & $\begin{array}{l}\text { First offer: } \\
\text { Pap test } \\
\text { Arm } B^{\star} \dagger \\
\text { Total=104 }\end{array}$ & $(\%)$ & p Value \\
\hline \multicolumn{6}{|l|}{ Age group (years) } \\
\hline $25-29$ & 12 & 15.4 & 15 & 14.4 & \\
\hline 30-34 & 8 & 10.3 & 16 & 15.4 & \\
\hline $35-39$ & 15 & 19.2 & 21 & 20.2 & \\
\hline $40-44$ & 5 & 6.4 & 13 & 12.5 & \\
\hline $45-49$ & 14 & 17.9 & 13 & 12.5 & $0.195 \ddagger$ \\
\hline $50-54$ & 6 & 7.7 & 10 & 9.6 & \\
\hline $55-59$ & 10 & 12.8 & 12 & 11.5 & \\
\hline $60-64$ & 3 & 3.8 & 2 & 1.9 & \\
\hline $65-69$ & 5 & 6.4 & 2 & 1.9 & \\
\hline$<50$ years of age & 54 & 69.2 & 78 & 75.0 & 0.388 \\
\hline First Nation & 71 & 91.0 & 94 & 90.4 & 0.882 \\
\hline On-Reserve & 35 & 44.9 & 79 & 76.0 & $<0.001$ \\
\hline \multicolumn{6}{|l|}{ Education } \\
\hline$<$ High school & 29 & 37.2 & 33 & 31.7 & 0.963 \\
\hline High school & 9 & 11.5 & 14 & 13.5 & \\
\hline Trade/tech school/college & 12 & 15.4 & 17 & 16.3 & \\
\hline University/college diploma & 21 & 26.9 & 30 & 28.8 & \\
\hline University degree & 6 & 7.7 & 8 & 7.7 & \\
\hline \multicolumn{6}{|l|}{ Employment } \\
\hline Currently employed & 45 & 57.7 & 60 & 57.7 & 0.556 \\
\hline Looking for work & 9 & 11.5 & 18 & 17.3 & \\
\hline Not looking for work & 15 & 19.2 & 17 & 16.3 & \\
\hline \multicolumn{6}{|l|}{ Food security } \\
\hline Often/sometimes worried, average of four questions§ & 21 & 26.9 & 29 & 27.9 & 0.885 \\
\hline
\end{tabular}

is still needed and is currently under way by the ACCSS team.

The large variability in the screening uptake within communities was equally noted for both arms, implying that the modality offered is not the only means to increase screening participation in our target population. Indeed, our data and the statement of one CBRA: "Easier for me, small community, I knew everyone who was in that age range", suggest that the approach of using lay health workers for recruitment is more effective in smaller communities and needs to be further explored. Variation in the number of participants per community is also likely to have resulted from individual engagement of the CBRAs. In addition, being new in a community may affect the outcome: in the community with the lowest uptake, the CBRA was at first very shy to approach women but is now well trusted and enthusiastic to continue her work with the ACCSS.

Interestingly, no significant differences of psychosocial scores were found between the two screening arms. This finding may be explained by the fact that approximately two-thirds of our questionnaire participants reported having had a Pap test within the timeframe of 3 years recommended in recent guidelines ${ }^{45}$ and implies that we have primarily reached women who already are regularly screened. The $\sim 30 \%$ 'underscreened' women of our cohort were equally distributed in both arms. Participation recruitment included individual (eg, door-to-door visits and in-person appointments) and communal (eg, educational events, health fairs and well women clinics) strategies, and were most successful with women under the age of 50 .

In conclusion, differences in uptake between both screening methods indicated a preference towards HPV self-sampling, but study participation was lower than what was expected. Long-term, the ACCSS with its longitudinal approach is poised to increase awareness for the benefit of cervical screening. In a recent gathering with selected members (HCPs and CBRAs) from all partner communities, the ACCSS team received positive feedback for this study and a request to continue the work. More collaborative work with the partner communities based on innovative, community-shaped health promotions and Indigenous knowledge-based education involving all ages and genders are necessary steps to elucidate ways in which to reach the women, who remain underscreened. 
Table 5 Health demography characteristics of women who provided a baseline questionnaire

\begin{tabular}{|c|c|c|c|c|c|}
\hline Type of characteristic & $\begin{array}{l}\text { First offer: HPV } \\
\text { self-sampling } \\
\text { Arm } A^{*} \dagger \\
\text { Total }=78\end{array}$ & $(\%)$ & $\begin{array}{l}\text { First offer: } \\
\text { Pap test } \\
\text { Arm } B^{\star} \dagger \\
\text { Total=104 }\end{array}$ & $(\%)$ & p Value \\
\hline \multicolumn{6}{|l|}{ Self-reported health status } \\
\hline Excellent & 1 & 1.3 & 10 & 9.6 & $0.118 \ddagger$ \\
\hline Very Good & 24 & 30.8 & 26 & 25.0 & \\
\hline Good & 37 & 47.4 & 53 & 51.0 & \\
\hline Fair & 13 & 16.7 & 10 & 9.6 & \\
\hline Poor & 3 & 3.8 & 3 & 2.9 & \\
\hline Use on-reserve healthcare & 43 & 55.1 & 45 & 43.3 & 0.113 \\
\hline Use traditional medicine & 9 & 11.5 & 11 & 10.6 & 0.838 \\
\hline \multicolumn{6}{|l|}{ Most recent Pap test prior to baseline questionnaire§ } \\
\hline$<6$ months & 5 & 6.4 & 18 & 17.3 & $0.586 \ddagger$ \\
\hline Between 6 months and 1 year & 14 & 17.9 & 16 & 15.4 & \\
\hline Between 1 and 3 years & 35 & 44.9 & 35 & 33.7 & \\
\hline More than 3 years & 17 & 21.8 & 33 & 31.7 & \\
\hline Pap test in 3 year interval prior to baseline questionnaire & 54 & 69.2 & 69 & 66.3 & 0.681 \\
\hline Abnormal Pap ever & 19 & 24.4 & 31 & 29.8 & 0.493 \\
\hline Receiving/completed treatment & 12 & 63.2 & 14 & 45.2 & 0.713 \\
\hline Reported a hysterectomy & 10 & 12.8 & 8 & 7.7 & 0.251 \\
\hline \multicolumn{6}{|l|}{ Residential school } \\
\hline Personally attended & 7 & 9.0 & 7 & 6.7 & 0.574 \\
\hline Parents/grandparents attended & 34 & 43.6 & 50 & 48.1 & 0.548 \\
\hline \multicolumn{6}{|l|}{ Health impact of residential school attendants } \\
\hline Favourable & 4 & 9.8 & 0 & 0.0 & 0.103 \\
\hline Adverse & 14 & 34.1 & 23 & 40.4 & \\
\hline No effect & 8 & 19.5 & 13 & 22.8 & \\
\hline Do not know/prefer not to answer & 9 & 22.0 & 16 & 28.1 & \\
\hline $\begin{array}{l}\text { *N (\%) unless otherwise specified. } \\
\dagger \text { Totals may not sum to } 100 \% \text { because of unanswered question, } \\
\text { †Linear-by-linear association test with exact } p \text { Value. } \\
\text { §Counts in rows 'Never' and 'Do not know' were removed becaus }\end{array}$ & $\begin{array}{l}\text { efer not to answe } \\
\text { oo low counts (0- }\end{array}$ & ot $\mathrm{kr}$ & responses. & iatic & \\
\hline
\end{tabular}

For instance, in a recent focus group promoting arts-integrated education to explain the cause of cervical cancer through HPV, the women created their own HPV balls based on an electron micrograph of the HPV capsid molecule, "turning something ugly into something beautiful" as one participant expressed it. ${ }^{46}$

\section{Author affiliations}

${ }^{1}$ Probe Development and Biomarker Exploration, Thunder Bay Regional Research Institute (TBRRI), Thunder Bay, Ontario, Canada

${ }^{2}$ Department of Biology, Lakehead University, Thunder Bay, Ontario, Canada ${ }^{3}$ Northern Ontario School of Medicine, Clinical Sciences, Thunder Bay, Ontario, Canada

${ }^{4}$ Biotechnology Program, Lakehead University, Thunder Bay, Ontario, Canada ${ }^{5}$ School of Epidemiology, Public Health and Preventive Medicine, University of Ottawa, Ottawa, Ontario, Canada

${ }^{6}$ Department of Pathology and Laboratory Medicine, Thunder Bay Regional Health Sciences Centre, Thunder Bay, Ontario, Canada

${ }^{7}$ Viral Exanthemata and STD Section, National Microbiology Laboratory, Public Health Agency of Canada, Winnipeg, Manitoba, Canada

${ }^{8} \mathrm{BC}$ Centre for Disease Control, Vancouver, British Columbia, Canada

${ }^{9}$ School of Population and Public Health, Faculty of Medicine, University of British Columbia, Vancouver, British Columbia, Canada

${ }^{10}$ Ontario HIV Treatment Network, Toronto, Ontario, Canada

${ }^{11}$ Dalla Lana School of Public Health, University of Toronto, Toronto, Ontario, Canada
Acknowledgements The authors thank the ACCSS First Nations partner communities in the Thunder Bay district, the CBRAs for their community engagement during both phases of the trial as well as the community management and leadership for their continuous support. They also thank $\mathrm{Dr}$ Pamela Wakewich and Mrs Melissa Togtema for critically reading the manuscript. Ann N Burchell is supported by a CIHR New Investigator Award. Gina Ogilvie holds a Canada Research Chair in Global Control of HPV-Related Disease and Cancer. Julian Little holds a Canada Research Chair in Human Genome Epidemiology.

Contributors IZ conceived and designed the study, completed all field work, including prior community engagement and formal community research agreements and led the writing of the manuscript. JL (senior author) contributed largely to the design of the ACCSS, supervised the analyses of the ACCSS trial data with $I Z$ and contributed to writing and critical revision of the manuscript. RJ performed all statistical analyses and largely contributed to writing the manuscript. BW assisted in the field work and design of the questionnaires, as well as in the analyses and in revision of the manuscript. BW supervised the biostatistics and contributed to writing the manuscript. NE contributed to the clinical aspects of this project, the critical communication with CytoBase to obtain Pap screening data and revision of the manuscript. AS and MK contributed to the HPV analyses and writing of this portion of the manuscript. LB contributed to the community field work during the ACCSS trial, to the analyses and critically revised the manuscript keeping in mind cultural safety. KM contributed to the field work in her own community and critically revised the manuscript keeping in mind cultural safety. ANB initially designed the ACCSS trial, significantly contributed to the design of the questionnaires and revision of the manuscript. GO contributed to the design 
of the ACCSS trial and revision of the manuscript. All authors have read and approved the final version of the manuscript and agreed to act as guarantors of the work therein.

Funding This work was funded by the Canadian Institutes of Health Research (ClHR) with IZ being the nominated Principal Investigator (CIHR \# MOP119344). This project has been sponsored by the Thunder Bay Regional Research Institute (TBRRI; 980 Oliver Road, Thunder Bay ON, P7B 6V4). Neither the CIHR nor the TBRRI were involved with the design of the study, the analyses or the writing of the manuscript.

Competing interests The ACCSS team received support from Roche Diagnostics (RD) for the HPV analyses of the self-collected samples. However, RD was not involved with the study design, the analyses or the writing of the manuscript.

Ethics approval The trial (ISRCTN84617261) was approved by the Lakehead University Research Ethics Board (\#126 12-13/ROMEO \#1463139).

Provenance and peer review Not commissioned; externally peer reviewed.

Data sharing statement No additional data are available.

Open Access This is an Open Access article distributed in accordance with the Creative Commons Attribution Non Commercial (CC BY-NC 4.0) license, which permits others to distribute, remix, adapt, build upon this work noncommercially, and license their derivative works on different terms, provided the original work is properly cited and the use is non-commercial. See: http:// creativecommons.org/licenses/by-nc/4.0/

\section{REFERENCES}

1. Ferlay J, Soerjomataram I, Ervik M, et al. GLOBOCAN 2012 v1.0, Cancer incidence and mortality worldwide: IARC CancerBase No. 11. Lyon, France: International Agency for Research on Cancer, 2013. http://globocan.iarc.fr (accessed 21 Jun 2014).

2. Quinn M, Babb P, Jones J, et al. Effect of screening on incidence of and mortality from cancer of cervix in England: evaluation based on routinely collected statistics. BMJ 1999;318:904-8.

3. Moore SP, Antoni S, Colquhoun A, et al. Cancer incidence in indigenous people in Australia, New Zealand, Canada and the USA a comparative population-based study. Lancet Oncol 2015;16:1483-92.

4. Marrett LD, Chaudhry M. Cancer incidence and mortality in Ontario First Nations, 1968 1991. Cancer Cause Control 2003;14:259-68.

5. Demers A, Kliewer E, Remes O, et al. Cervical cancer among Aboriginal women in Canada (Commentary). CMAJ 2012;18:743-4.

6. Colquhoun A, Jiang Z, Maiangowi G, et al. An investigation of cancer incidence in a First Nations community in Alberta, Canada, 1995-2006. Chronic Dis Can 2010;30:135-40.

7. Vasilevska M, Ross SA, Gesink D, et al. Relative risk of cervical cancer in indigenous women in Australia, Canada, New Zealand, and the United States: a systematic review and meta-analysis. J Public Health Policy 2012;33:148-64.

8. Huh WK, Ault KA, Chelmow D, et al. Use of primary high-risk human papillomavirus testing for cervical cancer screening: interim clinical guidance. Obstet Gynecol 2015;125:330-7.

9. Ogilvie GS, Krajden M, van Niekerk DJ, et al. Primary cervical cancer screening with HPV testing compared to liquid based cytology: results of round 1 of a randomized controlled trial-the HPV FOCAL Study. Br J Cancer 2012;107:1917-24.

10. Verdoodt $F$, Jentschke M, Hillemanns $P$, et al. Reaching women who do not participate in the regular cervical cancer screening programme by offering self-sampling kits: a systematic review and meta-analysis of randomised trials. Eur J Cancer 2015;51:2375-85.

11. Arrossi S, Thouyaret L, Herrero R, et al. Effect of self-collection of HPV DNA offered by community health workers at home visits on uptake of screening for cervical cancer (the EMA study): a population-based cluster-randomised trial. Lancet Glob Health 2015;3:e85-94.

12. Zehbe I, Moeller $\mathrm{H}$, Severini A, et al. Feasibility of self-sampling and human papillomavirus testing for cervical cancer screening in First Nation women from northwest Ontario, Canada: a pilot study. BM Open 2011; : e000030.

13. Wood B, Burchell AN, Escott N, et al. Using community engagement to inform and implement a community-randomized controlled trial in the Anishinaabek cervical cancer screening study. Front Oncol 2014;4:27.

14. Flicker S, Travers R, Guta A, et al. Ethical dilemmas in community-based participatory research: recommendations for institutional review boards. J Urban Health 2007;84:478-93.
15. Leykum LK, Pugh JA, Lanham HJ, et al. Implementation research design: integrating participatory action research into randomized controlled trials. Implement Sci 2009;4:69-77.

16. Maar M, Burchell A, Little J, et al. A qualitative study of provider perspectives of structural barriers to cervical cancer screening among First Nations women. Womens Health Issues 2013;23: e319-25.

17. Maar M, Wakewich $\mathrm{P}$, Wood B, et al. Strategies for increasing cervical cancer screening amongst First Nations Communities in northwest Ontario, Canada. Health Care Women Int 2014;6:1-18.

18. Wakewich $P$, Wood B, Davey $C$, et al. Colonial legacy and the experience of First Nations women in cervical cancer screening: a Canadian multi-community study. Crit Public Health 2015;26: 368-80.

19. Campbell MK, Elbourne DR, Altman DG, CONSORT Group. CONSORT statement: extension to cluster randomised trials. BMJ 2004;328:702-8.

20. Campbell MK, Piaggio G, Elbourne DR, et al. CONSORT Group Consort 2010 statement: extension to cluster randomised trials. BMJ 2012;345:e5661.

21. Chan A-W, Tetzlaff JM, Altman DG, et al. SPIRIT 2013 statement: defining standard protocol items for clinical trials. Ann Intern Med 2013;158:200-7.

22. Chan AW, Tetzlaff JM, Gøtzsche PC, et al. SPIRIT 2013 explanation and elaboration: guidance for protocols of clinical trials. $B M J$ 2013;346:e7586.

23. Aboriginal Affairs and Northern Development Canada. 2013 Indian Registration System (Communities, Age, Gender) [database]. https:// www.aadnc-aandc.gc.ca/eng/1291132820288/1291132853616\#stats (accessed 15 Jul 2014)

24. Murphy J, Kennedy EB, Dunn S, et al. Cervical Screening: a guideline for clinical practice in Ontario. J Obstet Gynaecol Can 2012;34:453-8.

25. Stenvall $\mathrm{H}$, Wikström I, Wilander E. High prevalence of oncogenic human papillomavirus in women not attending organized cytological screening. Acta Derm Venereol 2007;87:243-5.

26. Wikstrom I, Stenvall H, Wilander E. Attitudes to self-sampling of vaginal smear for human papillomavirus analysis among women not attending organized cytological screening. Acta Obstet Gynecol Scand 2007:86:720-5.

27. Sanner K, Wikström I, Strand A, et al. Self-sampling of the vaginal fluid at home combined with high-risk HPV testing. Br J Cancer 2009;101:871-4.

28. Gail MH, Mark SD, Carroll RJ, et al. On design considerations and randomization-based inference for community intervention trials. Stat Med 1996;15:1069-92.

29. Cosby RH, Howard M, Kaczorowski J, et al. Randomizing patients by family practice: sample size estimation, intracluster correlation and data analysis. Fam Pract 2003;20:77-82.

30. Redmond C, Colton T. Biostatistics in clinical trials. New York: John Wiley and Sons Ltd, 2008:56.

31. Giraudeau B, Ravaud P. Preventing bias in cluster randomised trials PLOS Med 2009;6:e1000065.

32. Hahn S, Puffer S, Torgerson DJ, et al. Methodological bias in cluster randomised trials. BMC Med Res Methodol 2005;5:10.

33. White IR, Carpenter J, Horton NJ. Including all individuals is not enough: lessons for intention-to-treat analysis. Clin Trials 2012;9:396-407.

34. Jo B, Asparouhov T, Muthén BO. Intention-to-treat analysis in cluster randomized trials with noncompliance. Stat Med 2008;27: 5565-77.

35. Rossi PG. Screening: the information individuals need to support their decision: per protocol analysis is better than intention-to-treat analysis at quantifying potential benefits and harms of screening. BMC Medical Ethics 2014;15:28.

36. Davison AC, Hinkley DV. Bootstrap methods and their application. Chapter 5. Cambridge, UK: Cambridge University Press, 1997.

37. Gray NM, Sharp L, Cotton SC, et al. Developing a questionnaire to measure the psychosocial impact of an abnormal cervical smear result and its subsequent management: the TOMBOLA (Trial of management of Borderline and Other Low-grade Abnormal smears) trial. Qual Life Res 2005;14:1553-62.

38. Rosen NO, Knäuper B, Di Dio P. The impact of intolerance of uncertainty on anxiety after receiving an informational intervention about HPV: a randomised controlled study. Psychol Health 2010;25:651-68.

39. Campbell I. Chi-squared and Fisher-Irwin tests of two-by-two tables with small sample recommendations. Stat Med 2007;26:3661-75.

40. Howell D. Treatment of ordered variables in a contingency table. 2007. http://www.uvm.edu/ dhowell/methods7/Supplements/ OrdinalChiSq.html (accessed 24 Apr 2015). 
41. Germain MF, Costa R, Kelly-Scott K. 2006 Aboriginal population profile for Thunder Bay (component of statistics canada catalogue no. 89-638-X no. 2009001). Apr 2009. http://www.statcan.gc.ca/pub/89638-x/2009001/article/10832-eng.pdf (accessed 26 Jul 2015).

42. Urban Aboriginal Population Study: Environics Institute, 2011. http:// www.uaps.ca/wp-content/uploads/2010/02/UAPS_Summary_Final. pdf (accessed 29 Jul 2015)

43. Statistics Canada. Health Fact Sheets (Publication 82-625-X). Household Food Insecurity. 2013. http://www.statcan.gc. ca/pub/82-625-x/2013001/article/11889-eng.htm (accessed 27 Apr 2014).
44. Racey CS, Withrow DR, Gesink D. Self-collected HPV testing improves participation in cervical cancer screening: a systematic review and meta-analysis. Can J Public Health 2013;104: e159-66.

45. Cancer Care Ontario, Toronto: Screening Guidelines 2014. Toronto. https://www.cancercare.on.ca/pcs/screening/cervscreening/ screening guidelines/ (accessed 26 Jul 2015)

46. Sameshima P, Slingerland D, Wakewich P, et al. Growing wellbeing through community participatory arts: the Anishinaabek Cervical Cancer Screening Study (ACCSS). The Palgrave Handbook of Global Arts Education. In press. 